\title{
The Relationship between Vitamin D Level and Incidence of Diabetic Peripheral Neuropathy in Diabetic patients type 2
}

\author{
Hind Mahmoud, Mohamed El-Azab, Maged Butros, AbdelNaser Mourad
}

\begin{abstract}
Department of Neurology, Faculty of Medicine Benha University, Egypt.

Correspondence to: Hind Mahmoud, Department of Neurology, Faculty of Medicine Benha University, Egypt.
\end{abstract}

Email:

hind88.h9@gmail.com

Received: 4 January 2020

Accepted: 30 August 2021

\begin{abstract}
Background: Vitamin D is mostly known for its essential role in the musculoskeletal system specially in Calcium and phosphorus metabolism, yet it is recently associated with different neurological disorders. Objective: To study the relationship between vitamin D level and diabetic peripheral neuropathy in diabetes type 2. Methods: A case-control study included 100 participants, 50 type 2 diabetic patients with diabetic peripheral neuropathy and 50 healthy controls. The patients included had clinical assessment and NCS. And all patients and control had assessment of BMI, fasting and 2-h pp blood sugar, $\mathrm{HbA} 1 \mathrm{C}$, and vitamin D level. Results: Serum vitamin D level was significantly lower in patients compared to control $(P$ value $=$ 0.001). For the patients group, females and patients with MNSI score more than 4 had significant lower vitamin D level ( $P$ value $=0.001$ and 0.001 , respectively). Significant negative correlation
\end{abstract} was found between vitamin D level and peroneal nerve latency ( $p$ value 0.048), otherwise no correlation between vit D level and results of nerve conduction study. Significant strong inverse correlation was found between vitamin D level and severity of PDN - MNSI scores - ( $p$ value 0.002). Conclusion: Low Vitamin D was highly prevalent in DPN patients. Females and patients with severer form of neuropathy are more liable for lower vitamin D levels.

Keywords: Diabetic peripheral neuropathy, Diabetes type2, Vitamin D, MNSI, NCS 


\section{Introduction}

The prevalence of diabetic peripheral neuropathy in newly diagnosed diabetic patients accounts for $8 \%$ and more than $50 \%$ in patients with longstanding disease [1]. Moreover, about $15 \%$ of all diabetic patients will develop foot ulcer [2] and greater than $50 \%$ of non-traumatic amputation of lower limbs is due to diabetes and its complications [3].

The pathogenesis of diabetic peripheral neuropathy is not fully understood. It is a multifactorial process and multiple hypotheses have been postulated, such as abnormal expression of sodium and calcium channels, metabolic and autoimmune disorders which lead to glial cell activation, blood vessel changes that affect the blood supply to the peripheral nerves and, recently, triggering of central pain mechanisms as a result of imbalance between the facilitatory/inhibitory descending pathways [4].

Overall, low vitamin D levels are associated with insulin resistance and obesity [5]. There is growing evidence that vitamin $\mathrm{D}$ has an important role in the prevention of islet cell death and may be beneficial to increase the survival of islet cell grafts [6]. Low 25hydroxyvitamin D levels have been associated with sensory neuropathy in diabetes and besides, vitamin D concentrations might be correlated with the severity of the neuropathy [7].
Studies in animal model of diabetes have depicted that treatment with vitamin $\mathrm{D}$ increases the level of nerve growth factor by stimulating its production and preventing its depletion. Nerve growth factor plays an vital role in the development and survival of sensory and sympathetic neurons [8].

The aim of this study is to review the relationship between vitamin D and incidence DPN in type 2 diabetes patients.

\section{Methods}

This study is a case control study that was conducted in Neurology department in Matarya Teaching Hospital in Cairo and during the period between December 2018 and September 2019, included 100 participants: 50 type 2 diabetic patients having DPN (18 males and 32 females) and 50 age, sex and, BMI matched healthy controls.

\section{Inclusion criteria:}

Diabetic patients with symmetrical peripheral polyneuropathy.

Diabetic patients were diagnosed according to American Diabetic Association criteria of 2015 [9] when one of the following criteria is fulfilled: 
- Fasting plasma glucose (FPG) $\geq 126 \mathrm{mg} / \mathrm{dL}$ (7.0 mmol/L) Fasting is defined as no caloric intake for $\geq 8$ hours.

- 2-hr PG $\geq 200 \mathrm{mg} / \mathrm{dL}$ (11.1 mmol/L) during oral glucose tolerance test (OGTT), using a glucose load enclosing the equivalent of $75 \mathrm{~g}$ anhydrous glucose dissolved in water.

- Hemoglobin A1C $\geq 6.5 \%$ (48 mmol/1).

- Random plasma glucose (PG) $\geq 200 \mathrm{mg} / \mathrm{dL}$ $(11.1 \mathrm{mmol} / \mathrm{L})$ in individuals with symptoms of hyperglycemia.

The MNSI score of all patients included in this study was of more than 2 [10].

\section{Exclusion criteria:}

- History of malignancy or degenerative disease of the nervous system.

- Diabetic macrovascular complications.

- Chronic hepatitis, pregnancy, and history of drug abuse.

- Renal impairment with renal replacement therapy and subjects on vitamin D supplementation.

Each participant gave a written informed consent in this study.

\section{$\underline{\text { Clinical assessment }}$}

Patients were subjected to clinical evaluation including detailed history taking focusing on the duration of diabetes mellitus, types of currently received treatment and symptoms of neuropathy ,BMI measurement, thorough neurological examination, Michigan Neuropathy Screening Instrument Physical assessment; MNSI is screening for the presence of diabetic neuropathy, It includes inspection of the feet for deformities, dry skin, nail or hair abnormalities, callous or infection, quantitative assessment of vibration sensation at the dorsum of the great toe, grading of ankle reflexes, and monofilament testing. Patients found positive on the MNSI (greater than 2 points on a 10-point scale) are considered neuropathic with both a high specificity (95\%) and sensitivity (80\%) [10].

\section{$\underline{\text { Laboratory assessment }}$}

Patients and control groups were subjected to the following laboratory investigations: fasting and $2 \mathrm{hpp}$ test and HbA1c test: HbA1c was categorized into good control: 5.5-6.8\%, fair control: 6.8-7.6\%, and poor control: > $7.6 \%[11]$.

Serum vitamin D level was measured in patients and control groups via Sat fax 303 Plus made in the USA Serum vitamin D level was categorized into sufficiency: more than $30 \mathrm{ng} / \mathrm{ml}$, insufficiency: between 20 and $30 \mathrm{ng} / \mathrm{ml}$, and deficiency: below $20 \mathrm{ng} / \mathrm{ml}$ [12]. 


\section{$\underline{\text { Neurophysiological assessment }}$}

All patients with DPN had Nerve conduction study done for them by Nihon Kohden@ Neuropack machine, Japan. The protocol used in this study was Ulnar and median nerves (motor and sensory parts) in the upper limbs, while in the lower limbs tibial nerve (motor part), peroneal nerve (motor), and sural nerve (sensory part).

\section{Statistical analysis}

\section{- The data were coded and entered using:} the statistical package for social science version 15 (SPSS v 15).

- The following parameters were used:

-Descriptive analysis of the results (minimum, maximum, mean and standard deviation) for quantitative data and the frequency distribution for qualitative data.

- Student t- test: for comparison between means of two groups of quantitative variables.

- Chi square test: for comparison between two groups of categorical data or frequency of events.

- P: $P$ value $\geq 0.05$ : Not significant $P$ value $<$ 0.05: Significant
The correlation coefficient (r): degree of relationship either positive or negative

\section{Results}

- The age of DPN patients ranged from 29 to 75 years with a mean value of $55.3 \pm \mathrm{SD}=10.25$ years, whereas the age of controls ranged from 29 to 73 years with a mean value of 52.80 $\pm \mathrm{SD}=10.65$ years. . Both of patients and control groups followed the same sex type dispersal (Table 1). The clinical characteristics of diabetic peripheral neuropathy patients, BMI, duration and types of medical treatment of diabetes mellitus, HBA1C, MNSI score, and diabetic neuropathy syndromes (established on clinical examination and neurophysiological studies) were shown in Table 2. All patients with DPN underwent NCS including ulnar and median nerves (both sensory and motor), tibial, peroneal and sural nerves. The Latency, amplitude and Velocity were evaluated (Table 3). 
Benha medical journal, vol. 38, issue 3, 2021

Table (1): Sex distribution among studied participants:

\begin{tabular}{cccc}
\hline Sex & \multicolumn{2}{c}{ patient / control } & Total \\
& patient & control & \\
\hline Male & 18 & 18 & 36 \\
Female & 32 & 32 & 64 \\
Total & 50 & 50 & 100 \\
\hline
\end{tabular}

Table 2: Clinical characteristics of diabetic peripheral neuropathy patients

\begin{tabular}{|c|c|c|}
\hline Clinical characteristics & & Patients (n \& \%) \\
\hline \multirow[t]{2}{*}{ BMI } & $\leq 24$ & $12 \%(\mathrm{n}=6)$ \\
\hline & $>24$ & $88 \%(n=44)$ \\
\hline \multirow{2}{*}{$\begin{array}{l}\text { Duration of Diabetes } \\
\text { Mellitus }\end{array}$} & $\leq 5$ years & $50 \%(\mathrm{n}=25)$ \\
\hline & $>5$ years & $50 \%(\mathrm{n}=25)$ \\
\hline \multirow{3}{*}{$\begin{array}{l}\text { treatment of Diabetes } \\
\text { mellitus }\end{array}$} & Insulin therapy & $52 \%(\mathrm{n}=26)$ \\
\hline & $\begin{array}{l}\text { Oral hypoglycemic } \\
\text { drugs }\end{array}$ & $40 \%(n=20)$ \\
\hline & Combination of both & $8 \%(n=4)$ \\
\hline \multirow{2}{*}{$\begin{array}{l}\text { Level of glycosylated } \\
\text { hemoglobin }\end{array}$} & Fair control (6.8-7.6) & $36 \%(\mathrm{n}=18)$ \\
\hline & Poor control (> 7.6) & $64 \%(n=32)$ \\
\hline \multirow[t]{2}{*}{ MNSI score } & $\leq 4$ & $54 \%(\mathrm{n}=27)$ \\
\hline & $>4$ & $46 \%(n=23)$ \\
\hline \multirow{4}{*}{$\begin{array}{l}\text { Detailed Neurological } \\
\text { Examination }\end{array}$} & Radiculopathy & $16 \%(\mathrm{n}=8)$ \\
\hline & $\begin{array}{l}\text { Carpal tunnel } \\
\text { syndrome }\end{array}$ & $10 \%(\mathrm{n}=5)$ \\
\hline & Sensory neuropathy & $18 \%(n=9)$ \\
\hline & Sensorimotor & $56 \%(\mathrm{n}=28)$ \\
\hline
\end{tabular}


Table (3): Descriptive measurement of NCS:

\begin{tabular}{|c|c|c|c|c|c|c|}
\hline Nerve & Normal N (\%) & Abnormal N (\%) & Minimum & Maximum & Mean & Std. Deviation \\
\hline Median Motor V. & $14(28)$ & $36(72)$ & 38.0 & 72.0 & 50.010 & 8.3336 \\
\hline Median Motor A. & $25(50)$ & $25(50)$ & 2.2 & 14.3 & 7.090 & 2.9217 \\
\hline Median Motor L. & $26(52)$ & $24(48)$ & 3.5 & 9.4 & 5.212 & 1.5971 \\
\hline Ulnar Motor V. & $32(64)$ & $18(36)$ & 38.0 & 70.0 & 51.832 & 7.1139 \\
\hline Ulnar Motor A. & $48(96)$ & 2(4) & 4.0 & 11.6 & 7.920 & 1.8187 \\
\hline Ulnar motor $\mathrm{L}$. & $42(84)$ & $8(16)$ & 2.5 & 7.3 & 4.062 & 1.4174 \\
\hline Peroneal V. & $34(68)$ & $16(32)$ & 30.0 & 55.0 & 42.300 & 6.9230 \\
\hline Peroneal A. & $40(80)$ & $10(20)$ & .3 & 7.0 & 3.084 & 1.6786 \\
\hline Peroneal L. & $26(52)$ & $24(48)$ & 3.3 & 14.9 & 6.970 & 3.1124 \\
\hline Tibial V. & $28(56)$ & $22(44)$ & 28.0 & 50.0 & 38.780 & 6.2465 \\
\hline Tibial A. & $32(64)$ & $18(36)$ & 1.50 & 15.00 & 6.2048 & 3.46890 \\
\hline Tibial L. & $30(60)$ & $20(40)$ & 2.6 & 16.0 & 6.912 & 3.8913 \\
\hline $\begin{array}{l}\text { Median Sensory } \\
\text { V. }\end{array}$ & $30(60)$ & $20(40)$ & 20.0 & 61.0 & 39.558 & 9.3261 \\
\hline $\begin{array}{l}\text { Median Sensory } \\
\text { A. }\end{array}$ & $32(64)$ & $18(363)$ & .11 & 39.00 & 17.8484 & 11.25911 \\
\hline $\begin{array}{l}\text { Median Sensory } \\
\text { L. }\end{array}$ & $22(44)$ & $28(56)$ & 2.6 & 8.0 & 4.576 & 1.5368 \\
\hline Ulnar Sensory V. & 48(96) & 2(4) & 32.0 & 60.4 & 48.372 & 7.6512 \\
\hline Ulnar Sensory A. & $34(68)$ & $16(32)$ & .11 & 43.60 & 16.9564 & 11.37072 \\
\hline Ulnar Sensory L. & $38(76)$ & $12(24)$ & 1.8 & 4.1 & 2.790 & .5512 \\
\hline Sural V. & $48(96)$ & $2(2)$ & 29.3 & 60.0 & 40.594 & 8.4254 \\
\hline Sural A & $32(64)$ & $18(36)$ & .1 & 18.0 & 6.332 & 4.9018 \\
\hline Sural L. & $24(48)$ & $26(52)$ & 2.3 & 12.0 & 4.860 & 1.8730 \\
\hline
\end{tabular}


The serum vitamin D level was assessed for each group control and diabetic peripheral neuropathy patient groups. The level in the patient group ranged from $10.2 \mathrm{ng} / \mathrm{ml}$ to 42 $\mathrm{ng} / \mathrm{ml}$ with a mean value $18.7 \pm 7.08 \mathrm{ng} / \mathrm{ml}$. While the level in the control group ranged from $17.7 \mathrm{ng} / \mathrm{ml}$ to $80.1 \mathrm{ng} / \mathrm{ml}$ with a mean value $37.96 \pm 15.39 \mathrm{ng} / \mathrm{ml}$. The vitamin D level was significantly lower in DPN patients $P$ value $=0.001($ Table 4$)($ Figure 1). Different vitamin $\mathrm{D}$ level categories in diabetic peripheral neuropathy patients and control groups are shown in Table 5.

In patient group, females had significantly lower vitamin $\mathrm{D}$ level than males $(P$ value $=$ 0.001) ( table 6 ) and diabetic peripheral neuropathy patients with MNSI score more than 4 had statistically significant lower vitamin D level compared to patients with MNSI score less than $4(\mathrm{P}$ value $=0.001)$ no statistically significant difference in the vitamin D level between patients age, DPN patients duration of diabetes, different treatment regimen and different $\mathrm{BMI}(\mathrm{P}$ value $=$ $0.65,0.42,0.75$ and 0.632 , respectively).

There was significant difference in vitamin D level between poor and fair glycemic control patients with p value (0.038) (table 7)

Correlation was carried between vitamin D level and the results of NCS. There was statistically significant inverse correlation between vitamin $\mathrm{D}$ and peroneal nerve latency only no correlation with other different values of the nerves included (Table 8).

There was strong significant negative correlation between MNSI and vitamin D with a P value of 0.002 (Table 9) (figure 2 ).

Table (4): Descriptive and comparative measurement of Vit D level among studied participants:

\begin{tabular}{ccccc}
\hline S. Vit D level & N & Mean ng/ml & Std. Deviation & P value \\
\hline Patient & 50 & 18.7400 & 7.08021 & 0.001 \\
Control & 50 & 37.9626 & 15.39408 & \\
\hline
\end{tabular}




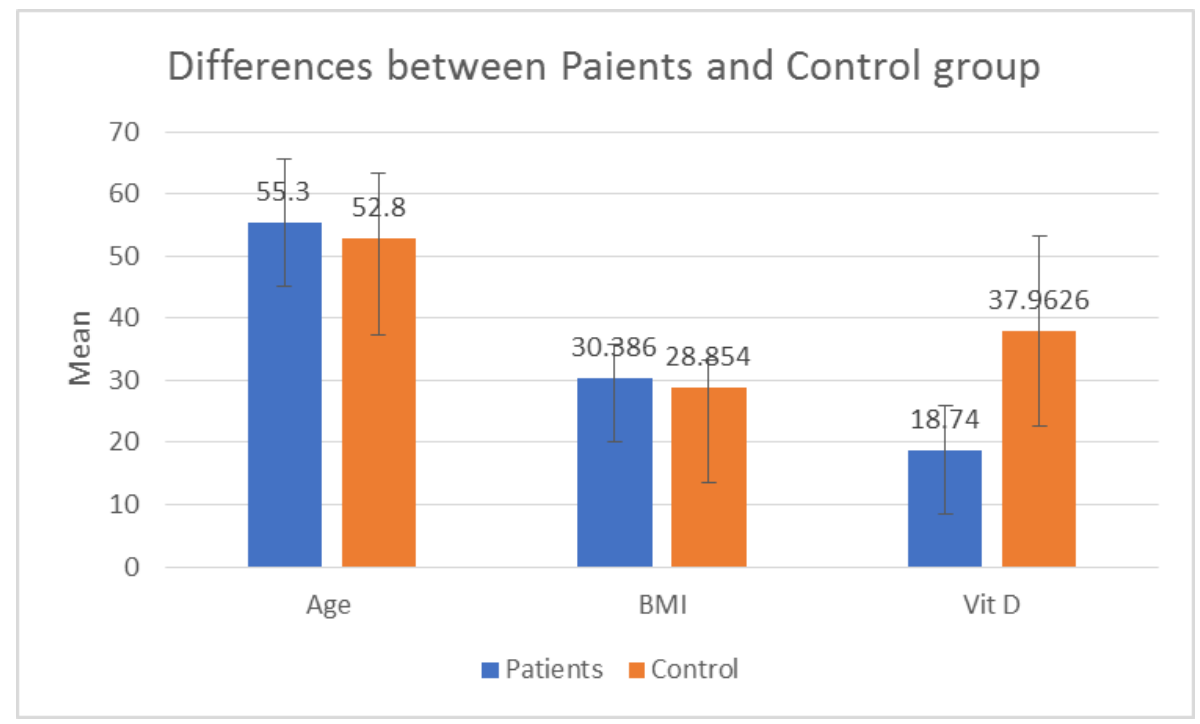

Figure (1): Differences between patients and controls regarding age, BMI , and Vitamin D level

Table (5): Classification of Vit D measurement in DPN patients:

\begin{tabular}{cccc}
\hline Vit D level & DPN patients (\%) N=50 & Mean \pm SD & Range (min., max) \\
\hline $\mathbf{1 0 - 2 0} \mathbf{~ n g / m l ~ ( D e f i c i e n c y ) ~}$ & $34(68.0 \%)$ & $14.98 \pm 2.59$ & $9.40(10.20-19.60)$ \\
$\begin{array}{c}\text { more than } \mathbf{2 0} \text { to } \mathbf{3 0} \mathbf{~ n g / m l} \\
(\text { Insufficiency) }\end{array}$ & $13(26.0 \%)$ & $23.68 \pm 2.82$ & $8.2(20.70-28.90)$ \\
more than $\mathbf{3 0} \mathbf{~ n g / m l ~ ( N o r m a l ) ~}$ & $3(6.0 \%)$ & $39.83 \pm 1.92$ & $3.7(38.30-42.00)$ \\
\hline
\end{tabular}

Table (6): Comparison between male \&female patients regarding serum Vitamin D level

\begin{tabular}{ccccccc}
\hline \multicolumn{2}{c}{ Studied Variables } & N & Mean ng/ml & Std. Deviation ng/ml & Std. Error Mean & P-value \\
\hline \multirow{2}{*}{ Vit D } & Male & 18 & 24.2444 & 8.55998 & 2.01761 & $0.001^{*}$ \\
& Female & 32 & 15.6437 & 3.40085 & .60119 & \\
\hline
\end{tabular}


Benha medical journal, vol. 38, issue 3, 2021

Table (7) : Comparison between vitamin D levels in different clinical situations in diabetic peripheral neuropathy patients

\begin{tabular}{|c|c|c|c|c|c|}
\hline \multicolumn{2}{|c|}{ Vit D Measurment } & \multirow{2}{*}{$\begin{array}{l}\mathbf{N} \\
13\end{array}$} & \multirow{2}{*}{$\begin{array}{l}\text { Mean } \\
17.9615\end{array}$} & \multirow{2}{*}{$\begin{array}{l}\text { Standard Deviation } \\
8.77891\end{array}$} & \multirow{2}{*}{$\frac{P \text { value }}{0.65}$} \\
\hline Age Category & 50 years or less & & & & \\
\hline & More than 50 years & 37 & 19.0135 & 6.49971 & \\
\hline \multirow[t]{2}{*}{ BMI } & Less than 24 & 6 & 30.3525 & 13.33661 & 0.632 \\
\hline & 24 and more & 44 & 28.0784 & 15.64507 & \\
\hline \multirow[t]{2}{*}{ MNSI } & 4or less & 27 & 21.5815 & 7.89484 & $0.001 *$ \\
\hline & More than 4 & 23 & 15.4043 & 4.05580 & \\
\hline \multirow{2}{*}{$\begin{array}{l}\text { Duration of } \\
\text { Diabetes }\end{array}$} & 5 years or less & 25 & 19.5480 & 7.47926 & 0.42 \\
\hline & More than 5 years & 25 & 17.9320 & 6.71179 & \\
\hline \multirow[t]{2}{*}{ HbA1C } & Fair control & 18 & 21.4944 & 8.75157 & $0.038^{*}$ \\
\hline & Poor control & 32 & 17.1906 & 5.50931 & \\
\hline \multirow{4}{*}{$\begin{array}{l}\text { Treatment } \\
\text { Regimen }\end{array}$} & Insulin therapy & 22 & 18.3636 & 6.61359 & 0.75 \\
\hline & Oral hypoglycemic drugs & 24 & 18.6625 & 7.54660 & \\
\hline & Combined therapy & 4 & 21.2750 & 8.14386 & \\
\hline & total & 50 & 18.7400 & 7.08021 & \\
\hline
\end{tabular}


Table (8): Correlation between Vitamin D and NCS:

\begin{tabular}{|c|c|c|}
\hline & \multicolumn{2}{|c|}{ Vit D } \\
\hline & $\mathbf{r}$ & P-value \\
\hline \multicolumn{3}{|c|}{ Median Motor } \\
\hline Velocity & -0.078 & 0.590 \\
\hline Latency & -0.086 & 0.551 \\
\hline Amplitude & -0.076 & 0.600 \\
\hline \multicolumn{3}{|c|}{ Ulnar Motor } \\
\hline Velocity & 0.054 & 0.711 \\
\hline Amplitude & -0.082 & 0.572 \\
\hline Latency & -0.051 & 0.723 \\
\hline \multicolumn{3}{|l|}{ Peroneal } \\
\hline Velocity & 0.088 & 0.544 \\
\hline Amplitude & -0.015 & 0.918 \\
\hline Latency & $-.281-^{*}$ & $0.048 *$ \\
\hline \multicolumn{3}{|l|}{ Tibial } \\
\hline Velocity & 0.014 & 0.923 \\
\hline Amplitude & -0.082 & 0.572 \\
\hline Latency & -0.251 & 0.079 \\
\hline \multicolumn{3}{|c|}{ Median Sensory } \\
\hline Velocity & 0.152 & 0.292 \\
\hline Amplitude & 0.061 & 0.673 \\
\hline Latency & -0.080 & 0.582 \\
\hline \multicolumn{3}{|c|}{ Ulnar Sensory } \\
\hline Velocity & -0.012 & 0.932 \\
\hline Amplitude & -0.131 & 0.365 \\
\hline Latency & -0.019 & 0.894 \\
\hline \multicolumn{3}{|l|}{ Sural } \\
\hline Velocity & 0.085 & 0.558 \\
\hline Amplitude & -0.193 & 0.179 \\
\hline Latency & -0.126 & 0.383 \\
\hline
\end{tabular}

(r) Using Pearson coefficient $\mathrm{P}$ value $\geq 0.05$ (non significant), and $* \mathrm{P}$ value $<0.05$ (significant).

Table (9): Correlation between Vitamin D level and MNSI

\begin{tabular}{lcc}
\hline & MNSI & \\
Vitamin D & (r) coefficient & P-value \\
& $-0.498^{* *}$ & 0.002 \\
\hline
\end{tabular}

(r) Using Pearson coefficient $\mathrm{P}$ value $\geq 0.05$ (non- significant), and $* \mathrm{P}$ value $<0.05$ (significant). 


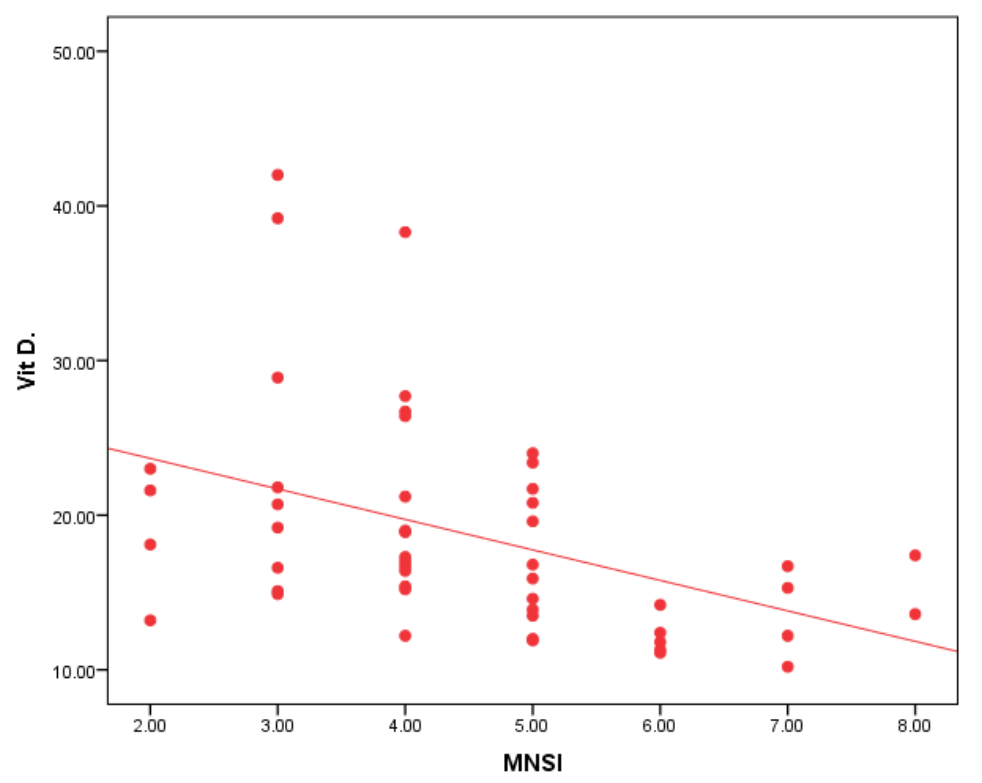

Figure (2): The inverse correlation between vitamin D level and MNSI

\section{Discussion}

Diabetic peripheral neuropathy is as a chief cause for disability. The prevalence of DPN is a matter of disease duration; of all patients with diabetes, eventually about 60 to $70 \%$ will develop DPN, even though not all will suffer pain [13].

The aim of this work was to study the relationship between vitamin $\mathrm{D}$ level and DPN.

The study was conducted on 50 type 2 diabetic patients with diabetic peripheral neuropathy and 50 healthy controls. 34 patients (68\%) had vitamin D deficiency, 13 patients (26\%) had vitamin D insufficiency and3 patients $(6 \%)$ had normal Vitamin .

Our findings are in accordance to the findings of others who established vitamin D deficiency in $64.2 \%$ of their patients and vitamin D insufficiency in 25\% and just 10.3\% had normal vitamin D level [14].

Supporting our findings, several recent studies found that serum vitamin $\mathrm{D}$ level in patients with diabetic peripheral neuropathy is significantly lower than that in healthy controls [15-17].

On the other hand, another two groups of researchers [18] and [19] found no difference in the prevalence of vitamin D deficiency between diabetic peripheral neuropathy patients and controls. The contradiction between those results and our findings can be explained by, first, 
using different methods for diagnosis of peripheral neuropathy (they only used vibration and monofilament) and, second, no NCS.

In this study, females with diabetic peripheral neuropathy had expressively lower $25(\mathrm{OH})$ level than males. Likewise Lebanese and Japanese studies found that female patients with type 2 DM also have had lower 25-OHD levels than males $[20,21]$. In contrast, in an Iranian study, there was no significant difference between both genders in vitamin D levels [22].

Gender difference in vitamin D level can be attributed to the interaction between circulating sex hormones and vitamin D. As the observed effects of vitamin D maybe related to testosterone [23]. Also, lactation and pregnancy are potential causes for vitamin $D$ deficiency [24]. Moreover, in the Arab world, women usually dress in long clothes that cover most of the surface of the skin [25].

Our study failed to detect a significant relation between age of patients and vitamin D. Corresponding to our study, Suzuki and colleagues [21] found no significant correlation between the age of type 2 DM patients and 25(OH)D level. In 2013 it was established that there was no significant difference between the serum 25(OH)D level of patients below the age of 40 and those above the age of 40 [26]. Unlike wise, other researchers, [22] and [27] found significant correlation between serum vitamin $D$ levels of type 2 diabetes patients and with their ages. In our study, there was a great variability in the disease duration and most of our patients had poor glycemic control, this may explain the insignificant relation between the age of patients and vitamin D level.

In this study, there was a significant relation between the level of $\mathrm{HbA} 1 \mathrm{c}$ and serum vitamin D level. Similarly, other studies demonstrated a negative correlation between $\mathrm{HbA} 1 \mathrm{C}$ and serum vitamin D level [21, 29].

On contrary, some studies [28] and [19] failed to detect a relationship between $\mathrm{HbA} 1 \mathrm{c}$ and serum 25-OH vitamin D levels and stated that HbA1C levels were similar across groups with different $25-\mathrm{OH}$ vitamin D concentrations.

In our study, peripheral neuropathy patients who scored MNSI more than 4 had a significantly lower serum vitamin D level. 
Similarly, in a study performed 2012 [30] it was found that Neuropathy Disability Score depicted significant positive correlation with vitamin D. Also, others [31] studied 143 individuals known to be type 2 diabetes with DPN and evaluated neuropathic pain using Douleur Neuropathique 4 (DN4) score, total McGill pain score, besides(SFMPQ) score, $40.5 \%$ patients showed evidence of vitamin D deficiency. A single intramuscular dose of 600,000 IU vitamin D resulted in a significant surge in vitamin D level and reduced the positive symptoms on the DN4, total pain score, and SFMPQ.

On the contrary, it was proved that there was no significant link between the level of 25 hydroxyvitamin D and the degree of severity of diabetic neuropathy. Different findings could be accredited for using diverse scores in the assessment of the severity of DPN [7].

For statistical purposes, we have categorized our patients according to duration of DM into: DPN patients with disease duration more than 5 years and less than 5 years. No significant difference was found between both groups in serum vitamin D level.

Likewise, the study done in Saudi Arabia shown insignificant difference between various serum vitamin D levels regarding disease duration (more and less than 5 years) [32]. In contrast, some others studied serum
25(OH) D in 337 Kurd patients with DM type 2 and found that serum $25(\mathrm{OH})$ D levels was statistically lower in patients with a diabetes duration more than 5 [26] .

The disagreement in the results could be explained by the different cutoff points used to categorize patients as on sufficient vitamin D status, the dissimilarity in the sample size of the patients.

In the present study, regarding serum vitamin D level there was no relation to whether the patients are presently receiving insulin, oral hypoglycemic drugs, or combined therapy. Similarly, in the study which included 706 type 2 diabetic patients with a wide range of age (20 to 93 years) found no statistically significant difference between users and nonusers of the oral hypoglycemic agent meforminas regards serum vitamin D level [33].

Numerous studies found that $25(\mathrm{OH})$ vitamin $\mathrm{D}$ levels of the insulin taking patients were lower than that of the oral hypoglycemic drug taking patients and control group. And that DM patients treated with insulin had the highest DPN prevalence [34-36].

These findings could be elucidated by the failure of diet and various oral hypoglycemic agents solely or in combination before starting insulin therapy. So, such patients could have several periods of poor glycemic control 
before the therapy was strengthened [14].

In our study, NCS including ulnar nerve (motor and sensory), median nerve (motor and sensory), tibial nerve (motor), peroneal nerve (motor), and sural nerve (sensory) was done to all patients and depicted no significant relation to different serum vitamin $\mathrm{D}$ levels.

Similarly, in 2012 a study was carried out on motor nerves including peroneal, tibial, median, and ulnar nerves and the sensory nerves including sural, median, and ulnar nerves. None of the NCS showed significant association with vitamin D [30].

No difference was observed in Neuropathy Disability Score and NCS after treatment [37].

\section{Conclusion}

Vitamin D deficiency was greatly prevalent in diabetic peripheral neuropathy patients in comparison to controls. Attention should be paid to the association between vitamin $\mathrm{D}$ and diabetic peripheral neuropathy and whether routine testing of serum vitamin D level in all DM patients have to bedone.

\section{Abbreviations \\ DPN: Diabetic peripheral Neuropathy., DM : Diabetes Miletus \\ 25(OH) D: 25-Hydroxyvitamin D; DM: Diabetes mellitus; DN4: Douleur Neuropathique 4; HbA1C: Hemoglobin A1C;}

MNSI: Michigan Neuropathy Screening Instrument; NSC: Nerve Conduction Study; SFMPQ: Short Form McGill Pain Questionnaire

\section{References:}

1. Boulton A, Malik R, Arezzo J, Sosenko J. Diabetic somatic neuropathies (technical review). Diabetes Care. 2004;27:1458-86.

2. Thomas P. Diabetic peripheral neuropathies: their cost to patient and society and the value of knowledge of risk factors for development of interventions. Eur Neurol. 1999;41(Suppl 1):35-43.

3. Dang C, Boulton A. Changing perspectives in diabetic foot ulcer management. Int $\mathrm{J}$ Low Extrem Wounds Mar. 2003;2(1):4-12.

4. Tesfaye S, Boulton A, Dyck P, Freeman R, Horowitz M, Kempler P, et al. Diabetic neuropathies: update on definitions, diagnostic criteria, estimation of severity, and treatments. Diabetes Care. 2010;33:2285-93.

5. Hahn S, Haselhorst U, Tan S, Quadbeck B, Schmidt M, Roesler S, et al. Low serum 25hydroxyvitamin D concentrations are associated with insulin resistance and obesity in women with polycystic ovary syndrome. Exp Clin Endocrinol Diabetes. 2006;114(10):577-83.

6. Riachy R, Vandewalle B, Moerman E, Belaich S, Lukowiak B, Gmyr V, et al. 1,25Dihydroxyvitamin D3 protects human pancreatic islets against cytokine-induced 
apoptosis via down-regulation of the Fas receptor. Apoptosis. 2006;11(2):151-9

7. Chaychi L, Mackenzie T, Bilotta D, Lynch M, Cohen J, Comi R. Association of serum vitamin D level with diabetic polyneuropathy. Medical Practice and Review. 2011;2(1):11-5.

8. Riaz S, Tomlinson D. Pharmacological modulation of nerve growth factor synthesis: a mechanistic comparison of vitamin D receptor and beta(2)-adrenoceptor agonists. Brain Res Mol. 2000;85:179-88.

9. American Diabetes Association. Diagnosis and classification of diabetes mellitus. Diabetes Care. 2015;38(Supplement 1):S8-S16.

10. Feldman EL, Stevens MJ, Thomas PK, et al. A practical two-step quantitative clinical and electrophysiological assessment for the diagnosis and staging of diabetic neuropathy. Diabetes Care. 1994;17:1281.

11. Sachin A. A study of plasma fibrinogen level in type-2 diabetes mellitus and its relation to glycemic control. Indian J Hematol Blood Transfus. 2012;28(2):105-8.

12. Lips P. Vitamin D physiology. Prog Biophys Mol Biol. 2006;92:4-8.

13. Juster-Switlyk K and Smith AG. Updates in diabetic peripheral neuropathy. F1000Research. 2016; 5:F1000 Faculty Rev738. doi:

14. Bayani M, Akbari R, Banasaz B, Saeedi F. (2014): Status of vitamin-D in diabetic patients. Caspian Journal of Internal Medicine. 2014;5(1):40-2.

15. Sarita B, Raj P, Dwivedi N, Kamaljeet S, Arvind G, Manoj M. Vitamin D levels and microvascular complications in type 2 diabetes. Indian $\mathrm{J}$ Endocrinol Metab. 2014;18(4):537-41.

16. Asuman C, Ayse G, Nermin T, Elif B, Mehmet A, Mehmet C, et al. Decreased serum vitamin D levels are associated with diabetic peripheral neuropathy in a rural area of Turkey. Acta Neurol Belg. 2015;115:47-52.

17. Bulent B, Feti T, Betul E, Sonat P, Tulay Y, Seyit A, et al. The association of vitamin D with inflammatory cytokines in diabetic peripheral neuropathy. J Phys Ther Sci. 2016;28:2159-63.

18. Tahrani A, Ball A, Shepherd L, Rahim A, Jones A, Bates A. The prevalence of vitamin D abnormalities in South Asians with type 2 diabetes mellitus in the UK. Int J Clin Pract. 2010;64:351-5.

19.Usluogullari C, Balkan F, Caner S, Ucler R, Kaya C, Ersoy R, et al. The relationship between microvascular complications and vitamin $\mathrm{D}$ deficiency in type 2 diabetes mellitus. BMC Endocrine Disorders. $2015 ; 25: 15-33$.

20.Ahmadieh H, Azar S, Lakkis N, Arabi A. Hypovitaminosis D in patients with type 2 diabetes mellitus: a relation to disease control and complications. ISRN Endocrinol. 2013;2013:641098. 
21.Suzuki A, Kotake M, Ono Y, Kato T, Oda N, Hayakawa N, Hashimoto S, Itoh $\mathrm{M}$. Hypovitaminosis D in type 2 diabetes mellitus: association with microvascular complications and type of treatment. Endocr J. 2006;53(4):503-10.

22. Leila M, Reza M, Sadoughi M, Beigrezaei S. Vitamin D status and its relationship with age in type 2 diabetic patients. Journal of Parathyroid Disease. 2017;5(2):45-8.

23. Seeman E. Unresolved issues in osteoporosis in men. Rev Endocr Metab Disord. 2001;2:4564.

24.Langlois K, Greene-Finestone L, Little J, Hidiroglou N, Whiting S. Vitamin D status of Canadians as measured in the 2007 to 2009 Canadian Health Measures Survey. Health Rep. 2010;21:47-55.

25.Saliba W, Rennert H, Kershenbaum RG. Serum $25(\mathrm{OH}) \mathrm{D}$ concentrations in sunny Israel. Osteoporos Int. 2012;23(2):687-94.

26.Al-Timimi D, Ali A. Serum 25(OH) D in diabetes mellitus type 2: relation to glycaemic control. J Clin Diagn Res. 2013;7(12):2686-8.

27.Kafeshani M, Zarafshani M, Shokri-Moghaddam S, Ahmadi A, Nasri H. Serum 25-hydroxy vitamin $\mathrm{D}$ level in diabetic patients versus normal individuals; a pilot study. J Parathyr Dis. 2016;42:41.

28.Olt S. Relationship between vitamin D and glycemic control in patients with type 2 diabetes mellitus. Int $\mathrm{J}$ Clin Exp Med. 2015;8(10):19180-3.
29.Buhary B, Almohareb O, Aljohani N, Alrajhi S, Elkaissi S, Sherbeeni S, et al. Association of glycosylated hemoglobin levels with vitamin D status. J Clin Med Res. 2017;9(12):1013-8.

30. Shehab D, Al-Jarallah K, Mojiminiyi O, Al Mohamedy H, Abdella N. Does vitamin D deficiency play a role in peripheral neuropathy in type 2 diabetes? Diabet Med. 2012;29(1):43-9.

31.Basit A, Basit K, Fawwad A, Shaheen F, Fatima $\mathrm{N}$, Petropoulos I, et al. Vitamin D for the treatment of painful diabetic neuropathy. BMJ Open Diabetes Research \& Care. 2016;4(1):e000148.

32.Al-Agha A, Ahmad I. Association among vitamin D deficiency, type 1 diabetes mellitus and glycemic control. J Diabetes Metab. 2015;6:594.

33.Kos E, Liszek MJ, Emanuele MA, DurazoArvizu R, Camacho P. Effect of metformin therapy on vitamin $\mathrm{D}$ and vitamin $\mathrm{B}_{12}$ levels in patients with type 2 diabetes mellitus. Endocr Pract. 2012;18(2):179-84.

34.Franklin G, Shetterly S, Cohen J, Baxter J, Hamman R. Risk factors for distal symmetric neuropathy in NIDDM. The San Luis Valley diabetes study. Diabetes Care. 1994;17(10):1172-7.

35.Pop-Busui R, Lu J, Lopes N, Jones T, BARI 2D investigators. Prevalence of diabetic peripheral neuropathy and relation to glycemic control therapies at baseline in the BARI 2D cohort. J Peripher Nerv Syst. 2009;14(1):1-13. 
Benha medical journal, vol. 38, issue 3, 2021

36.Boyraz I, Bilge U, Ünalacak M, Bilgin M. The comparison of $25(\mathrm{OH})$ vitamin D level in type

2 diabetes patients taking oral anti-diabetics and insulin. Biomed Res. 2016;27(1):24-8.
37.Shehab D, Al-Jarallah K, Abdella N, Mojiminiyi $\mathrm{O}, \mathrm{Al} \mathrm{MH}$. Prospective evaluation of the effect of short-term oral vitamin D supplementation on peripheral neuropathy in type 2 diabetes mellitus. Med Princ Pract. 2015;24(3):250-6

To cite this article: Hind Mahmoud, Mohamed El-Azab, Maged Butros, AbdelNaser Mourad. The Relationship between Vitamin D Level and Incidence of Diabetic Peripheral Neuropathy in Diabetic patients type 2. BMFJ 2021; 38(3): 908-924. DOI: 10.21608/bmfj.2021.21906.1200 